NISTIR 8239

\title{
Performance of an ISA100.11a Industrial Wireless Network with Wi-Fi Interference
}

\author{
Mohamed Kashef \\ Richard Candell
}

This publication is available free of charge from:

https://doi.org/10.6028/NIST.IR.8239

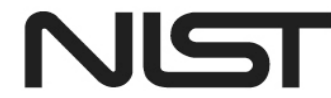

National Institute of Standards and Technology U.S. Department of Commerce 
NISTIR 8239

\title{
Performance of an ISA100.11a Industrial Wireless Network with Wi-Fi Interference
}

\author{
Mohamed Kashef \\ Advanced Network Technologies Division \\ Information Technology Laboratory \\ Richard Candell \\ Intelligent Systems Division \\ Engineering Laboratory
}

This publication is available free of charge from:

https://doi.org/10.6028/NIST.IR.8239

November 2018

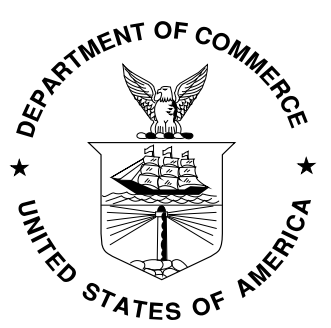

U.S. Department of Commerce Wilbur L. Ross, Jr., Secretary

National Institute of Standards and Technology Walter Copan, NIST Director and Undersecretary of Commerce for Standards and Technology 


\begin{abstract}
In this report, we present network measurement of an ISA100.11a industrial wireless network operating in the presence of WiFi interference. The IEEE 802.15.4-based ISA100.11a wireless protocol operates at the $2.4 \mathrm{GHz}$ band for various industrial applications. IEEE $802.11 \mathrm{WiFi}$ also may operate at the $2.4 \mathrm{GHz}$ band for industrial and data applications in the same environment. The existence of IEEE 802.11 wireless network would have a negative impact on the rated performance parameters of the ISA100.11a networks. In this work, we study WiFi interference impacts on the performance of a single ISA100.11a node using the National Institute of Standards and Technology (NIST) wireless testbed.
\end{abstract}

\title{
Key words
}

Industrial Wireless; Interference; Measurement Criteria.

\section{Acknowledgments}

NIST would like to thank Toshi Hasegawa, Kin-ichi Kitano, and Penny Chen at Yokogawa Corporation for providing engineering contributions and the ISA100.11a equipment used for this study. 


\section{Table of Contents}

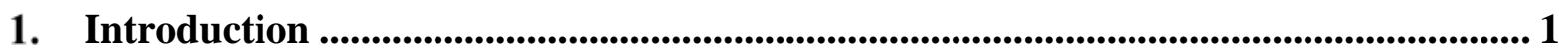

2. Testbed Description .......................................................................................... 2

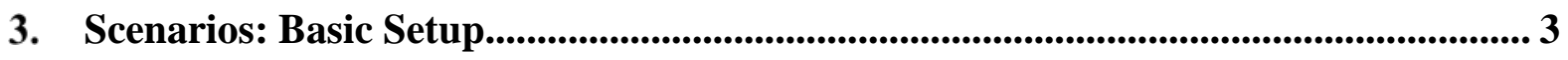

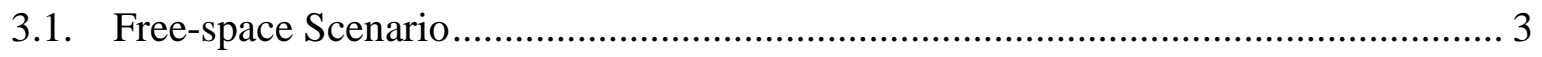

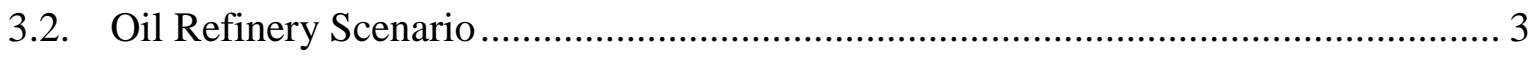

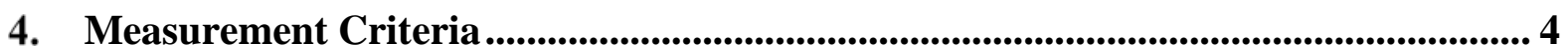

4.1. Signal Level Criteria ...................................................................................... 4

4.2. Network Level Criteria.................................................................................. 4

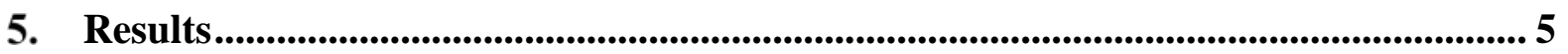

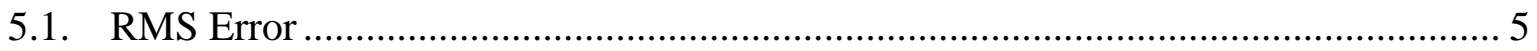

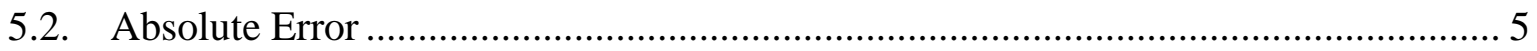

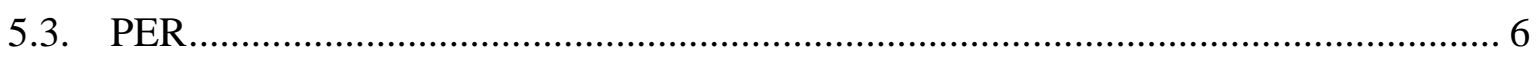

5.4. PER vs Absolute Error (Free-space) ................................................................. 6

5.5. PER vs Absolute Error (Oil Refinery) .................................................................. 7

5.6. End-to-End Average Signal Delay in Seconds................................................ 7

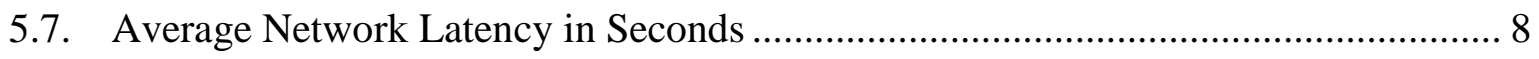

5.8. Maximum Network Latency in Seconds ........................................................... 8

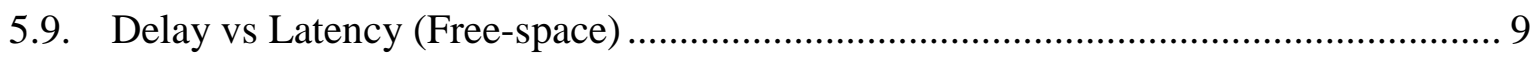

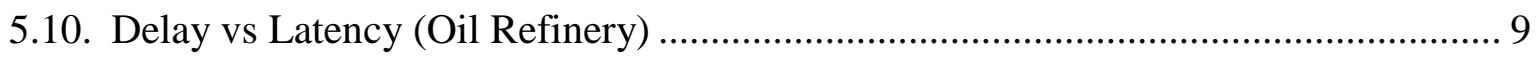

5.11. Normalized Peak Cross-Correlation.................................................................... 10

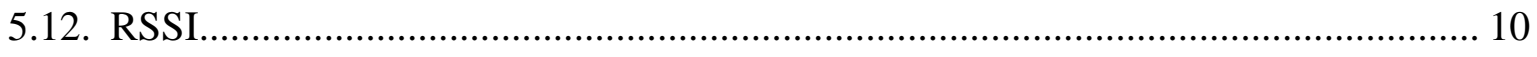

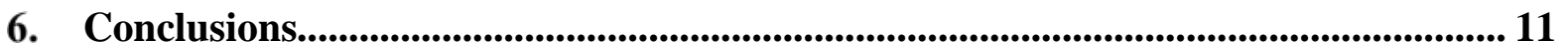




\section{Introduction}

The use of wireless sensor networks (WSN) in industrial automation offers several advantages compared to their wired counterparts. It obviously adds more flexibility of the network setup by eliminating the need for cabling, which reduces the network installation cost as well. Additionally, the deployment of WSN allows for improved productivity and better system management by increasing the number of sensors and collecting larger amounts of data. However, the practical implementation of WSN faces some challenges. One of the main challenges is the interference by other existing wireless devices in the industrial environment. Many industrial wireless protocols, including ISA100.11a, operate in the unlicensed $2.4 \mathrm{GHz}$ frequency band. That allows for the WSN to be more exposed to interference by both industrial and non-industrial wireless networks. WiFi is considered one of the major sources of interference in the $2.4 \mathrm{GHz}$ frequency band.

In the report, we have studied with a team from Yokogawa Corporation ${ }^{1}$ the effect of WiFi interference on the performance of ISA100.11a WSN composed of Yokogawa equipment. Yokogawa has developed a number of products for industrial WSN. Their products are developed to operate in typical industrial environments including refineries and chemical plants. We used the National Institute of Standards and Technology (NIST) wireless testbed to evaluate the performance of the ISA100.11a networks with the existence of controlled WiFi interference. The testbed contains a radio frequency (RF) channel emulator to replicate the industrial environment.

In this report, we present slides containing the results obtained during a visit of the Yokogawa team to NIST where the experiments took place. The enclosed presentation slides were prepared by NIST staff to document the activities and results of the collaboration with Yokogawa, and were presented by NIST to the Yokogawa team during their visit. This publication provides the material as presented and discussed at this meeting in its original form. We start with the testbed description where the components and their roles in the system are briefly discussed. Two testing scenarios are then described and their parameters are quantified, including the levels and type of WiFi interference. In each scenario, the corresponding channel parameters are mentioned. Then, two classes of measurement criteria are considered, namely, network-level and signal-level criteria. In each class, the definitions of the criteria are stated. The results are then specified where comparisons between the two scenarios and the comparable signal-level and network-level criteria are done. Finally, conclusions are drawn.

${ }^{1}$ Commercial equipment and materials are identified to adequately specify certain procedures. In no case does such identification imply recommendation or endorsement by the National Institute of Standards and Technology, nor does it imply that the materials or equipment identified are necessarily the best available for the purpose. 


\section{Testbed Description}

- The testbed includes a highperformance programmable logic controller (PLC) to produce the input signal $x(t)$.

- The network is composed of ISA100.11a wireless sensors and a gateway for infrastructure connectivity between nodes.

- A vector signal generator with an arbitrary waveform output is used to produce the WiFi interference signal.

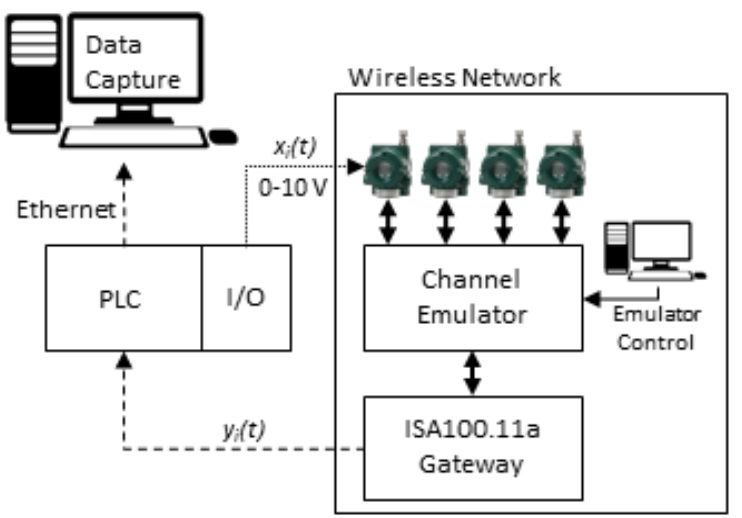

Figure 1 Testbed Architecture

- The testbed includes a radio channel emulator capable of replicating the multi-path and path loss environments for a mesh network of up to 8 physical nodes.

- The output of the wireless network $y(t)$ is compared to the input to measure various error and delay criteria.

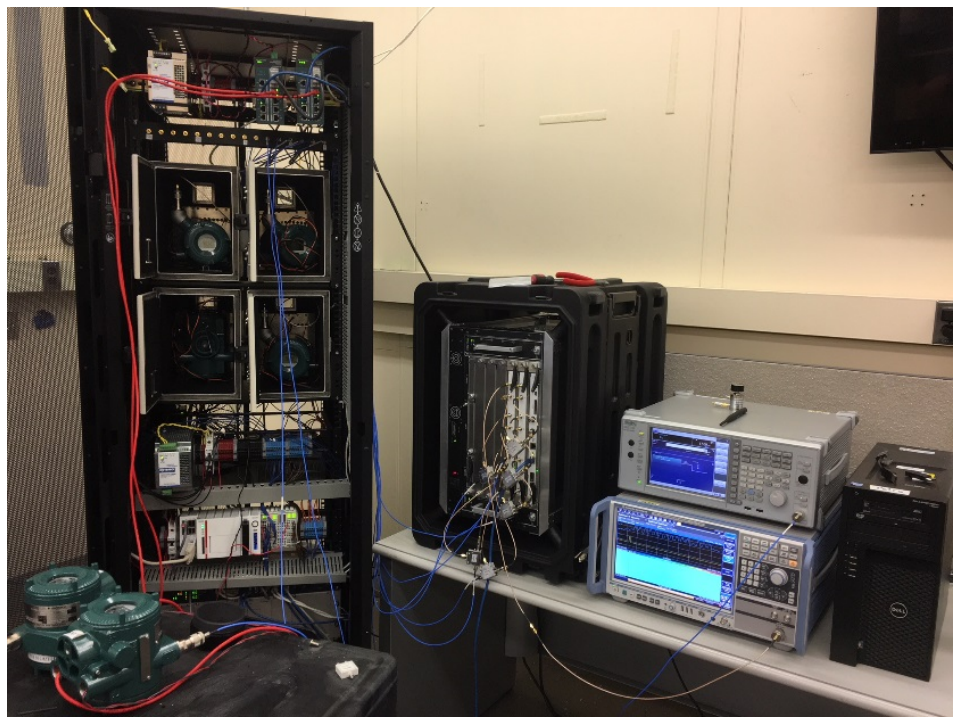

Figure 2 A Photo of the NIST Industrial Wireless Testbed 


\section{Scenarios: Basic Setup}

- The system is composed of a single WiFi sensor, gateway, and WiFi interferer.

- The system studied for various sensorgateway and interferer-gateway distances (dashed lines).

- Two scenarios are studied: "Freespace" and "Oil Refinery" where the wireless channels are different in the loss exponent and the channel impulse response (CIR).

- The wireless channels effects are generated using the channel emulator.

\subsection{Free-space Scenario}

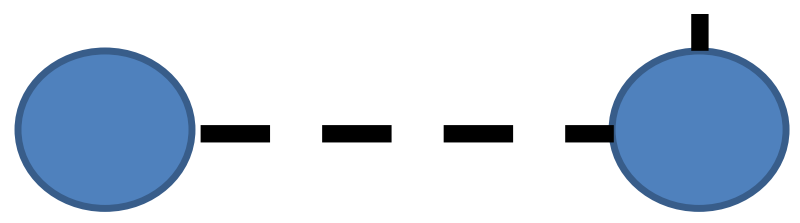

Sensor

- $\quad$ Loss Exponent = 2 (i.e., an isotropic radiator)

- Ideal Channel Impulse Response (No Multipath)

- Three different distances between the sensor and the Gateway $\{100 \mathrm{~m}, 180 \mathrm{~m}, 260 \mathrm{~m}\}$

- The injected interference is WiFi IEEE 802.11n (20 MHz Bandwidth) transmitting at $17 \mathrm{dBm}$ on channel 6 with a 50\% duty cycle.

- Three different settings for the interferer

\subsection{Oil Refinery Scenario}

- $\quad$ Loss Exponent = 2.7

- Channel Impulse Response is IEEE 802.15.4a LOS.

- $\quad$ Three different distances between the sensor and the Gateway $\{10 \mathrm{~m}, 30 \mathrm{~m}, 50 \mathrm{~m}\}$

- The interference is WiFi IEEE 802.11n (20 MHz Bandwidth) transmitting at 17dBm, channel 6 , and $50 \%$ duty cycle.

- Three different settings for the interferer \{No Interference, $5 \mathrm{~m}, 15 \mathrm{~m}$ from the Gateway\} 


\section{Measurement Criteria}

- Two classes of measurement criteria are considered

- Signal level and network level

- The signal level criteria are obtained through comparing the input and output analog signals.

- The network level criteria are obtained through a network monitoring tool provided by the device manufacturer and dealing with transmitted and received data packets.

- A maximal length pulse code is used as the input signal with each pulse have a 2 second pulse width.

\subsection{Signal Level Criteria}

- $\quad$ Root Mean Square (RMS) Error

$$
\min _{d} \sqrt{\frac{1}{T} \int_{0}^{T}(x(t-d)-y(t))^{2} d t}
$$

- Average Absolute Error

$$
\min _{d} \frac{1}{T} \int_{0}^{T}|(x(t-d)-y(t))| d t
$$

- Normalized Peak Cross Correlation

$$
\max _{d} \frac{\int_{0}^{T} x(t-d) y(t) d t}{\int_{0}^{T} x^{2}(t) d t}
$$

- $\quad$ End-to-End Delay

$$
\underset{d}{\operatorname{argmax}} \int_{0}^{T} x(t-d) y(t) d t
$$

\subsection{Network Level Criteria}

- Packet Error Rate (PER)

The number of error packets divided by the total number of received packets.

- Average Latency

The average time it takes for a packet of data to get from one designated point to another.

- Maximum Latency

The maximum time it takes for a packet of data to get from one designated point to another.

- $\quad$ Received Signal Strength Indicator (RSSI)

The relative received signal strength in a wireless environment which is an indication of the power level being received by the receive radio. 


\section{Results}

\subsection{RMS Error}

Table 1 Free-space

\begin{tabular}{|c|c|c|c|}
\hline & $100 \mathrm{~m}(-82 \mathrm{~dB})$ & $180 \mathrm{~m}(-85 \mathrm{~dB})$ & $260 \mathrm{~m}(-88 \mathrm{~dB})$ \\
\hline No Interference & 0.3361 & 0.3419 & 0.3978 \\
\hline $15 \mathrm{~m}(-64 \mathrm{~dB})$ & 0.3877 & 0.3884 & 0.4136 \\
\hline $5 \mathrm{~m}(-54 \mathrm{~dB})$ & 0.3955 & 0.4129 & 0.4590 \\
\hline
\end{tabular}

Table 2 Oil Refinery

\begin{tabular}{|c|c|c|c|}
\hline & $10 \mathrm{~m}$ & $30 \mathrm{~m}$ & $50 \mathrm{~m}$ \\
\hline No Interference & 0.3118 & 0.3329 & 0.3532 \\
\hline $15 \mathrm{~m}$ & 0.3556 & 0.3593 & 0.3639 \\
\hline $5 \mathrm{~m}$ & 0.3618 & 0.3883 & 0.3953 \\
\hline
\end{tabular}

\subsection{Absolute Error}

Table 3 Free-space

\begin{tabular}{|c|c|c|c|}
\hline & $100 \mathrm{~m}(-82 \mathrm{~dB})$ & $180 \mathrm{~m}(-85 \mathrm{~dB})$ & $260 \mathrm{~m}(-88 \mathrm{~dB})$ \\
\hline No Interference & 0.1130 & 0.1169 & 0.1583 \\
\hline $15 \mathrm{~m}(-64 \mathrm{~dB})$ & 0.1503 & 0.1509 & 0.1710 \\
\hline $5 \mathrm{~m}(-54 \mathrm{~dB})$ & 0.1565 & 0.1705 & 0.2107 \\
\hline
\end{tabular}

Table 4 Oil Refinery

\begin{tabular}{|c|c|c|c|}
\hline & $100 \mathrm{~m}(-82 \mathrm{~dB})$ & $180 \mathrm{~m}(-85 \mathrm{~dB})$ & $260 \mathrm{~m}(-88 \mathrm{~dB})$ \\
\hline No Interference & 0.1130 & 0.1169 & 0.1583 \\
\hline $15 \mathrm{~m}(-64 \mathrm{~dB})$ & 0.1503 & 0.1509 & 0.1710 \\
\hline $5 \mathrm{~m}(-54 \mathrm{~dB})$ & 0.1565 & 0.1705 & 0.2107 \\
\hline
\end{tabular}




\subsection{PER}

Table 5 Free-space

\begin{tabular}{|c|c|c|c|}
\hline & $100 \mathrm{~m}(-82 \mathrm{~dB})$ & $180 \mathrm{~m}(-85 \mathrm{~dB})$ & $260 \mathrm{~m}(-88 \mathrm{~dB})$ \\
\hline No Interference & $0 \%$ & $2 \%$ & $22 \%$ \\
\hline $15 \mathrm{~m}(-64 \mathrm{~dB})$ & $12 \%$ & $15 \%$ & $34 \%$ \\
\hline $5 \mathrm{~m}(-54 \mathrm{~dB})$ & $19 \%$ & $36 \%$ & $56 \%$ \\
\hline
\end{tabular}

Table 6 Oil Refinery

\begin{tabular}{|c|c|c|c|}
\hline & $10 \mathrm{~m}$ & $30 \mathrm{~m}$ & $50 \mathrm{~m}$ \\
\hline No Interference & $0 \%$ & $0 \%$ & $0 \%$ \\
\hline $15 \mathrm{~m}$ & $0 \%$ & $0 \%$ & $5 \%$ \\
\hline $5 \mathrm{~m}$ & $1 \%$ & $13 \%$ & $14 \%$ \\
\hline
\end{tabular}

\subsection{PER vs Absolute Error (Free-space)}

Table 7 PER

\begin{tabular}{|c|c|c|c|}
\hline & $100 \mathrm{~m}(-82 \mathrm{~dB})$ & $180 \mathrm{~m}(-85 \mathrm{~dB})$ & $260 \mathrm{~m}(-88 \mathrm{~dB})$ \\
\hline No Interference & $0 \%$ & $2 \%$ & $22 \%$ \\
\hline $15 \mathrm{~m}(-64 \mathrm{~dB})$ & $12 \%$ & $15 \%$ & $34 \%$ \\
\hline $5 \mathrm{~m}(-54 \mathrm{~dB})$ & $19 \%$ & $36 \%$ & $56 \%$ \\
\hline
\end{tabular}

Table 8 Absolute Error

\begin{tabular}{|c|c|c|c|}
\hline & $100 \mathrm{~m}(-82 \mathrm{~dB})$ & $180 \mathrm{~m}(-85 \mathrm{~dB})$ & $260 \mathrm{~m}(-88 \mathrm{~dB})$ \\
\hline No Interference & 0.1130 & 0.1169 & 0.1583 \\
\hline $15 \mathrm{~m}(-64 \mathrm{~dB})$ & 0.1503 & 0.1509 & 0.1710 \\
\hline $5 \mathrm{~m}(-54 \mathrm{~dB})$ & 0.1565 & 0.1705 & 0.2107 \\
\hline
\end{tabular}




\subsection{PER vs Absolute Error (Oil Refinery)}

Table 9 PER

\begin{tabular}{|c|c|c|c|}
\hline & $10 \mathrm{~m}$ & $30 \mathrm{~m}$ & $50 \mathrm{~m}$ \\
\hline No Interference & $0 \%$ & $0 \%$ & $0 \%$ \\
\hline $15 \mathrm{~m}$ & $0 \%$ & $0 \%$ & $5 \%$ \\
\hline $5 \mathrm{~m}$ & $1 \%$ & $13 \%$ & $14 \%$ \\
\hline
\end{tabular}

Table 10 Absolute Error

\begin{tabular}{|c|c|c|c|}
\hline & $10 \mathrm{~m}$ & $30 \mathrm{~m}$ & $50 \mathrm{~m}$ \\
\hline No Interference & 0.1090 & 0.1108 & 0.1247 \\
\hline $15 \mathrm{~m}$ & 0.1265 & 0.1291 & 0.1253 \\
\hline $5 \mathrm{~m}$ & 0.1309 & 0.1508 & 0.1609 \\
\hline
\end{tabular}

\subsection{End-to-End Average Signal Delay in Seconds}

Table 11 Free-space

\begin{tabular}{|c|c|c|c|}
\hline & $100 \mathrm{~m}(-82 \mathrm{~dB})$ & $180 \mathrm{~m}(-85 \mathrm{~dB})$ & $260 \mathrm{~m}(-88 \mathrm{~dB})$ \\
\hline No Interference & 2 & 2.5 & 3 \\
\hline $15 \mathrm{~m}(-64 \mathrm{~dB})$ & 2.5 & 2.5 & 3 \\
\hline $5 \mathrm{~m}(-54 \mathrm{~dB})$ & 2.5 & 3 & 3.5 \\
\hline
\end{tabular}

Table 12 Oil Refinery

\begin{tabular}{|c|c|c|c|}
\hline & $10 \mathrm{~m}$ & $30 \mathrm{~m}$ & $50 \mathrm{~m}$ \\
\hline No Interference & 2 & 2 & 2.5 \\
\hline $15 \mathrm{~m}$ & 2 & 2 & 2.5 \\
\hline $5 \mathrm{~m}$ & 2 & 2.5 & 2.5 \\
\hline
\end{tabular}




\subsection{Average Network Latency in Seconds}

Table 13 Free-space

\begin{tabular}{|c|c|c|c|}
\hline & $100 \mathrm{~m}(-82 \mathrm{~dB})$ & $180 \mathrm{~m}(-85 \mathrm{~dB})$ & $260 \mathrm{~m}(-88 \mathrm{~dB})$ \\
\hline No Interference & 0.5 & 0.6 & 0.9 \\
\hline $15 \mathrm{~m}(-64 \mathrm{~dB})$ & 0.6 & 0.7 & 1.1 \\
\hline $5 \mathrm{~m}(-54 \mathrm{~dB})$ & 0.8 & 1 & 1.2 \\
\hline
\end{tabular}

Table 14 Oil Refinery

\begin{tabular}{|c|c|c|c|}
\hline & $10 \mathrm{~m}$ & $30 \mathrm{~m}$ & $50 \mathrm{~m}$ \\
\hline No Interference & 1.1 & 1.2 & 1.2 \\
\hline $15 \mathrm{~m}$ & 1.1 & 1.2 & 1.2 \\
\hline $5 \mathrm{~m}$ & 1.1 & 1.2 & 1.2 \\
\hline
\end{tabular}

\subsection{Maximum Network Latency in Seconds}

Table 15 Free-space

\begin{tabular}{|c|c|c|c|}
\hline & $100 \mathrm{~m}(-82 \mathrm{~dB})$ & $180 \mathrm{~m}(-85 \mathrm{~dB})$ & $260 \mathrm{~m}(-88 \mathrm{~dB})$ \\
\hline No Interference & 1.2 & 1.3 & 2 \\
\hline $15 \mathrm{~m}(-64 \mathrm{~dB})$ & 1.3 & 1.3 & 3.6 \\
\hline $5 \mathrm{~m}(-54 \mathrm{~dB})$ & 1.5 & 3.3 & 7.5 \\
\hline
\end{tabular}

Table 16 Oil Refinery

\begin{tabular}{|c|c|c|c|}
\hline & $10 \mathrm{~m}$ & $30 \mathrm{~m}$ & $50 \mathrm{~m}$ \\
\hline No Interference & 1.3 & 1.3 & 1.3 \\
\hline $15 \mathrm{~m}$ & 1.3 & 1.3 & 1.3 \\
\hline $5 \mathrm{~m}$ & 1.3 & 1.3 & 1.3 \\
\hline
\end{tabular}




\subsection{Delay vs Latency (Free-space)}

Table 17 End-to-End Average Signal Delay in Seconds

\begin{tabular}{|c|c|c|c|}
\hline & $100 \mathrm{~m}(-82 \mathrm{~dB})$ & $180 \mathrm{~m}(-85 \mathrm{~dB})$ & $260 \mathrm{~m}(-88 \mathrm{~dB})$ \\
\hline No Interference & 2 & 2.5 & 3 \\
\hline $15 \mathrm{~m}(-64 \mathrm{~dB})$ & 2.5 & 2.5 & 3 \\
\hline $5 \mathrm{~m}(-54 \mathrm{~dB})$ & 2.5 & 3 & 3.5 \\
\hline
\end{tabular}

Table 18 Average Network Latency in Seconds

\begin{tabular}{|c|c|c|c|}
\hline & $100 \mathrm{~m}(-82 \mathrm{~dB})$ & $180 \mathrm{~m}(-85 \mathrm{~dB})$ & $260 \mathrm{~m}(-88 \mathrm{~dB})$ \\
\hline No Interference & 0.5 & 0.6 & 0.9 \\
\hline $15 \mathrm{~m}(-64 \mathrm{~dB})$ & 0.6 & 0.7 & 1.1 \\
\hline $5 \mathrm{~m}(-54 \mathrm{~dB})$ & 0.8 & 1 & 1.2 \\
\hline
\end{tabular}

\subsection{Delay vs Latency (Oil Refinery)}

Table 19 End-to-End Average Signal Delay in Seconds

\begin{tabular}{|c|c|c|c|}
\hline & $10 \mathrm{~m}$ & $30 \mathrm{~m}$ & $50 \mathrm{~m}$ \\
\hline No Interference & 2 & 2 & 2.5 \\
\hline $15 \mathrm{~m}$ & 2 & 2 & 2.5 \\
\hline $5 \mathrm{~m}$ & 2 & 2.5 & 2.5 \\
\hline
\end{tabular}

Table 20 Average Network Latency in Seconds

\begin{tabular}{|c|c|c|c|}
\hline & $10 \mathrm{~m}$ & $30 \mathrm{~m}$ & $50 \mathrm{~m}$ \\
\hline No Interference & 1.1 & 1.2 & 1.2 \\
\hline $15 \mathrm{~m}$ & 1.1 & 1.2 & 1.2 \\
\hline $5 \mathrm{~m}$ & 1.1 & 1.2 & 1.2 \\
\hline
\end{tabular}




\subsection{Normalized Peak Cross-Correlation}

Table 21 Free-space

\begin{tabular}{|c|c|c|c|}
\hline & $100 \mathrm{~m}(-82 \mathrm{~dB})$ & $180 \mathrm{~m}(-85 \mathrm{~dB})$ & $260 \mathrm{~m}(-88 \mathrm{~dB})$ \\
\hline No Interference & 0.8823 & 0.8818 & 0.8305 \\
\hline $15 \mathrm{~m}(-64 \mathrm{~dB})$ & 0.8479 & 0.8485 & 0.8419 \\
\hline $5 \mathrm{~m}(-54 \mathrm{~dB})$ & 0.8410 & 0.8349 & 0.7589 \\
\hline
\end{tabular}

Table 22 Oil Refinery

\begin{tabular}{|c|c|c|c|}
\hline & $10 \mathrm{~m}$ & $30 \mathrm{~m}$ & $50 \mathrm{~m}$ \\
\hline No Interference & 0.8945 & 0.8910 & 0.8799 \\
\hline $15 \mathrm{~m}$ & 0.8709 & 0.8623 & 0.8614 \\
\hline $5 \mathrm{~m}$ & 0.8667 & 0.8620 & 0.8611 \\
\hline
\end{tabular}

\subsection{RSSI}

Table 23 Free-space

\begin{tabular}{|c|c|c|c|}
\hline & $100 \mathrm{~m}(-82 \mathrm{~dB})$ & $180 \mathrm{~m}(-85 \mathrm{~dB})$ & $260 \mathrm{~m}(-88 \mathrm{~dB})$ \\
\hline No Interference & $-90 \mathrm{dBm}$ & $-91 \mathrm{dBm}$ & $-91 \mathrm{dBm}$ \\
\hline $15 \mathrm{~m}(-64 \mathrm{~dB})$ & $-90 \mathrm{dBm}$ & $-93 \mathrm{dBm}$ & $-90 \mathrm{dBm}$ \\
\hline $5 \mathrm{~m}(-54 \mathrm{~dB})$ & $-90 \mathrm{dBm}$ & $-93 \mathrm{dBm}$ & $-90 \mathrm{dBm}$ \\
\hline
\end{tabular}

Table 24 Oil Refinery

\begin{tabular}{|c|c|c|c|}
\hline & $10 \mathrm{~m}$ & $30 \mathrm{~m}$ & $50 \mathrm{~m}$ \\
\hline No Interference & $-54 \mathrm{dBm}$ & $-66 \mathrm{dBm}$ & $-71 \mathrm{dBm}$ \\
\hline $15 \mathrm{~m}$ & $-51 \mathrm{dBm}$ & $-64 \mathrm{dBm}$ & $-70 \mathrm{dBm}$ \\
\hline $5 \mathrm{~m}$ & $-49 \mathrm{dBm}$ & $-64 \mathrm{dBm}$ & $-70 \mathrm{dBm}$ \\
\hline
\end{tabular}




\section{Conclusions}

- There is less performance variations in the case of the oil refinery with realistic channel impulse response compared to the free-space case.

- The interference has larger effect at edges of the communications range of the network.

- The signal level performance criteria, which are more representative to the system performance, are more robust to the channel variations and the interference.

- Network latency does not represent a major part in the signal end-to-end delay. As a result, interference has a small effect on end-to-end delay.

- Wi-Fi interference may degrade the performance significantly in industrial environments and hence its use has to be monitored and controlled. 